Revue des patrimoines

46 | 2022

Le patrimoine de la Justice

\title{
Le présidial de Limoges : édifier une réforme de la justice à la fin de l'Ancien Régime
}

The présidial of Limoges: building justice reform at the end of the

Ancien Regime

Laure Leroux

\section{OpenEdition}

Journals

Édition électronique

URL : https://journals.openedition.org/insitu/33860

DOI : 10.4000/insitu.33860

ISSN : $1630-7305$

Éditeur

Ministère de la Culture

\section{Référence électronique}

Laure Leroux, "Le présidial de Limoges : édifier une réforme de la justice à la fin de l'Ancien Régime », In Situ [En ligne], 46 | 2022, mis en ligne le 16 janvier 2022, consulté le 04 février 2022. URL : http:// journals.openedition.org/insitu/33860 ; DOI : https://doi.org/10.4000/insitu.33860

Ce document a été généré automatiquement le 4 février 2022

\section{(i) $९$}

In Situ Revues des patrimoines est mis à disposition selon les termes de la licence Creative Commons Attribution - Pas d'Utilisation Commerciale - Pas de Modification 4.0 International. 


\section{Le présidial de Limoges : édifier une réforme de la justice à la fin de l'Ancien Régime}

The présidial of Limoges: building justice reform at the end of the Ancien Regime

Laure Leroux

Situé au cœur de Limoges, au voisinage de l'une des plus anciennes églises de la ville, Saint-Michel-des-Lions, le présidial constitue l'un des monuments emblématiques du paysage urbain. Édifié entre 1778 et 1782, sa façade imposante a été inscrite au titre des monuments historiques en $1947^{1}$ [fig. 1]. Laissé inoccupé depuis les années 1990, il a fait l'objet en 2018 d'une réhabilitation par une société privée visant à transformer ses amples espaces en appartements. 
Figure 1

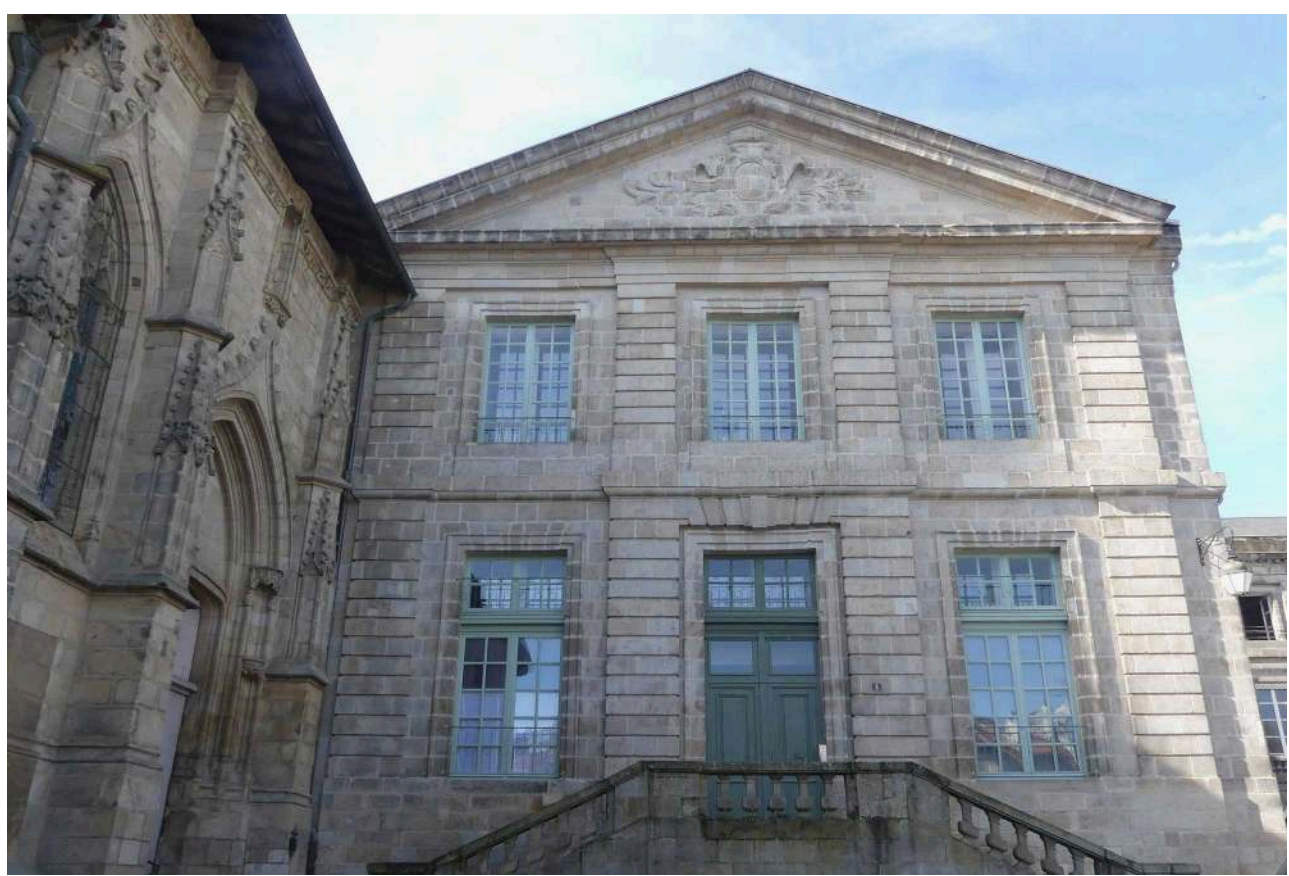

La façade du Présidial après restauration, contre l'église Saint-Michel des Lions-Limoges, 2021.

(C) Laure Leroux (Hadès²).

Dès décembre 2017, l'association Archéa est intervenue sur les cavités découvertes dans ses soubassements dans le cadre de ses recherches sur les souterrains de Limoges ${ }^{3}$. Outre une exploration minutieuse, deux de ses membres, Éric Balbo, accompagné de Jean-Claude Grany, ont procédé à un relevé lasergrammétrique exhaustif de ces souterrains afin d'en obtenir une imagerie numérique, sauvegardant ainsi l'essentiel des données concernant ces aménagements anciens avant leur scellement définitif ${ }^{4}$. Les travaux étaient également encadrés par les services de la direction régionale des Affaires culturelles de Nouvelle-Aquitaine : outre la restauration de la façade par un architecte du patrimoine, un accord a été conclu pour préserver une partie des cellules des prisons. Patrice Conte, médiéviste et ingénieur au service régional de l'Archéologie de Nouvelle-Aquitaine, convaincu de l'intérêt historique du monument, a prescrit des investigations archéologiques visant à approfondir la connaissance de l'édifice avant les modifications induites par les travaux. La démarche était innovante, pour une thématique étroitement corrélée aux sources écrites, mais les travaux de Mathieu Vivas en avaient démontré le potentiel archéologique, à propos des modalités d'exercice de la justice ${ }^{5}$. Les investigations concernant le présidial de Limoges confirment la légitimité de l'archéologie à investir cette problématique, y compris pour les périodes modernes et contemporaines. Nos travaux de recherche articulaient une analyse archéologique de l'architecture du bâtiment et une surveillance archéologique des travaux, en bonne intelligence avec le chef maçon, livrant une quarantaine d'épaves lapidaires issues de constructions antérieures au présidial actuel. L'accès aux archives du présidial, facilité par $\mathrm{M}^{\text {me }}$ Claire Gravelat (conservation régionale des Monuments historiques), chargée du dossier devant la Commission régionale des monuments historiques, a permis une confrontation convaincante des données archéologiques avec les sources historiques. Des recherches bibliographiques ont également été menées afin d'inscrire l'archéologie du présidial dans l'évolution urbaine de Limoges, au demeurant fort complexe, et de 
l'éclairer par les travaux universitaires des dernières décennies ayant trait à l'histoire de la justice. Le rapport de fouilles finalisant ces diverses investigations a bénéficié de l'étroite collaboration d'Éric Balbo pour les souterrains, inaccessibles lors de l'intervention archéologique du fait de l'avancement des travaux, pérennisant ainsi l'investissement associatif dans la sauvegarde de ce patrimoine judiciaire et limougeaud ${ }^{6}$.

3 Le présidial a fait l'objet de recherches dès la fin du $\mathrm{XIX}^{\mathrm{e}}$ siècle ${ }^{7}$, parmi une floraison de publications érudites sur la ville de Limoges ${ }^{8}$. Par la suite, si les publications sont plus anecdotiques, elles ne sont pas dénuées d'intérêt car elles se fondent sur des sources archivistiques ${ }^{9}$. Dans un article paru en 1999, le professeur d'histoire moderne Michel Cassan s'est intéressé au déclin de l'activité juridique du présidial ${ }^{10}$. L'un de ses doctorants, Vincent Meyzie, s'attache au monument ${ }^{11}$ et signale la modernité de la démarche adoptée dans l'élaboration du projet architectural, qui avait associé étroitement le maître d'œuvre, un ingénieur des Ponts et Chaussées, et les magistrats présidiaux. Ce processus est renseigné par les projets, plans et devis présentés par le maitre d'œuvre, auxquels répondent les magistrats ${ }^{12}$. Les sources archivistiques documentent également l'avancement des travaux, par les prix-faits des entrepreneurs en bâtiment et la correspondance entre le maître d'œuvre, l'intendant de Limoges et les diverses institutions urbaines. Ce pan de la documentation, peu exploité jusqu'alors, a servi les problématiques archéologiques: conjugué à l'analyse du bâti et de la topographie urbaine, il s'est agi d'esquisser les transformations du site antérieures au présidial actuel, mais également de confirmer la réalité du projet architectural et ses ajustements éventuels.

\section{De la place du Belvédère au présidial d'Henri II}

\section{Autour de Saint-Michel-des-Lions, la pérennité d'un lieu de justice}

Dès la fin de l'Antiquité, l'urbanisme de Limoges s'organise autour de deux pôles : la Cité, dominant la Vienne, siège du pouvoir épiscopal, et le tombeau de saint Martial, autour duquel se développe une influente communauté monastique [fig. 2]. Au x siècle, les rivalités s'exacerbent face à un autre protagoniste, le vicomte de Limoges, dont la motte est établie en contre-haut de l'enclos abbatial ${ }^{13}$, au voisinage de l'église SaintMichel-des-Lions ${ }^{14}$. 
Figure 2

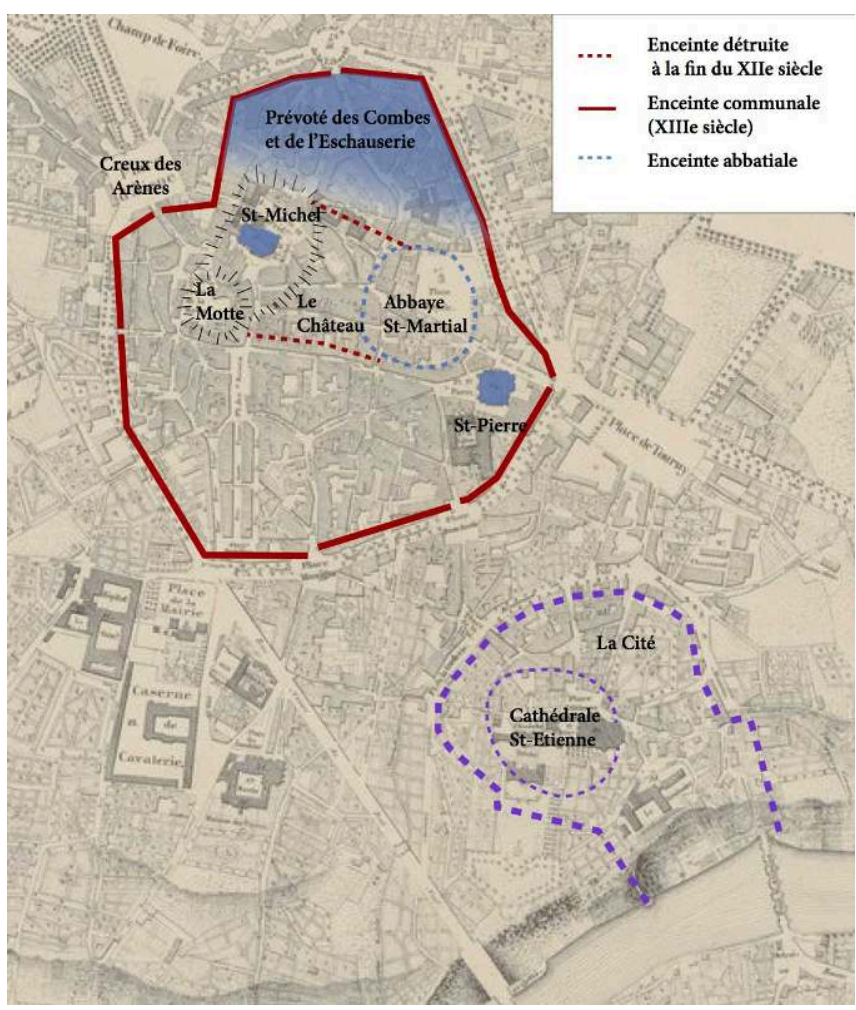

Ville et cité de Limoges à l'époque médiévale, 2019. Fond de plan extrait de Plan géométrique et topographique de la ville de Limoges, J.-B. Tripon, 1834.

Reproduction du fond de plan https://gallica.bnf.fr/ark:/12148/btv1b530280909.r=Limoges\%201594? rk=21459;2 [lien valide en octobre 2021] / (C) DAO Laure Leroux, d'après B. Barrière 1984.

5 Les traditions locales considèrent cette dernière comme l'une des plus anciennes églises de Limoges et la découverte de sarcophages présumés alto-médiévaux aux alentours de l'édifice suggère effectivement une occupation ancienne. La place située immédiatement au nord de cette église, qui constitue de nos jours la place du Présidial, était intitulée, à l'époque médiévale, carrefour du Belvédère, signalant une éminence topographique. Les sources de la fin du $\mathrm{xvI}^{\mathrm{e}}$ siècle confirment cette disposition, identifiant cette place au point culminant du paysage urbain, objet de divers complots pour s'emparer de la ville ${ }^{15}$. Si les grandes politiques d'urbanisme menées à partir du XVIII ${ }^{\mathrm{e}}$ siècle ont estompé ce relief, les abrupts des rues voisines attestent de sa réalité ${ }^{16}$.

6 Cette topographie constitue l'un des indices du choix du site comme lieu de justice dès la période médiévale, correspondant à l'imagerie traditionnelle de la colline figurée par l'iconographie judiciaire du Moyen Âge ${ }^{17}$. Un cimetière lié à l'église, s'étendant jusqu'à la rue des Fossés jusqu'en 1535, était également à même d'accueillir une assistance nombreuse lors des audiences et condamnations de justice, selon une pratique fréquente pour la période médiévale ${ }^{18}$. Un autre indice tient à la localisation du lieu au contact de deux juridictions, ainsi qu'en témoigne un texte médiéval indiquant le bornage de la prévôté des Combes, relevant de l'abbaye Saint-Martial, par le carrefour du Belvédère, à proximité de la motte vicomtale (voir figure 4). La titulature de l'église voisine apparaît tout aussi significative : outre qu'elle constitue une dédicace fréquente en contexte castral, la liturgie chrétienne attribue à saint Michel le jugement des âmes, la psychostasie. L'épigraphie de l'une des cloches de l'église, datée de 1431, rappelle 
explicitement ce double rôle ${ }^{19}$ : SANCTE MICHAEL, ARCHANGELE, DEFFENDE NOS IN PRELIO/ UT NON PEREAMUS IN TREMENDO JUDICIO ${ }^{20}$.

Les sources du XVI ${ }^{e}$ siècle apportent des preuves plus concrètes quant à l'identification de ce lieu de justice puisqu'en 1513, l'assassinat du lieutenant général du sénéchal de Limoges Pierre Bermondet de Cromières donne lieu au jugement par contumace de son meurtrier, le vicomte de Rochechouart François de Mortemart, et à l'érection d'une croix sur le lieu de son exécution symbolique, la place du Belvédère ${ }^{21}$. L'intervention du sénéchal, officier du vicomte de Limoges, laisse deviner que ce lieu de justice relevait du pouvoir vicomtal, le siège de la sénéchaussée se situant alors dans la tour du Breuil, bordant la place du Belvédère. Une confirmation plus explicite encore nous est livrée par un plan daté de 1594 [fig. 3] sur lequel figure, à l'arrière-plan de l'église SaintMichel, une place au centre de laquelle se situe un enclos rectangulaire que surplombe un pilier. Ce dernier rappelle l'arbre de justice, symbolisant l'axe du monde dans l'iconographie traditionnelle de la justice, et permet l'identification de l'enclos à un parquet de justice ${ }^{22}$. La représentation de ce dernier dans le plan de la ville signale son importance dans le paysage urbain; elle est d'autant plus remarquable qu'à la même période il côtoie le "palais de justice", également légendé sur le plan, et qui correspond à l'ancien présidial.

Figure 3

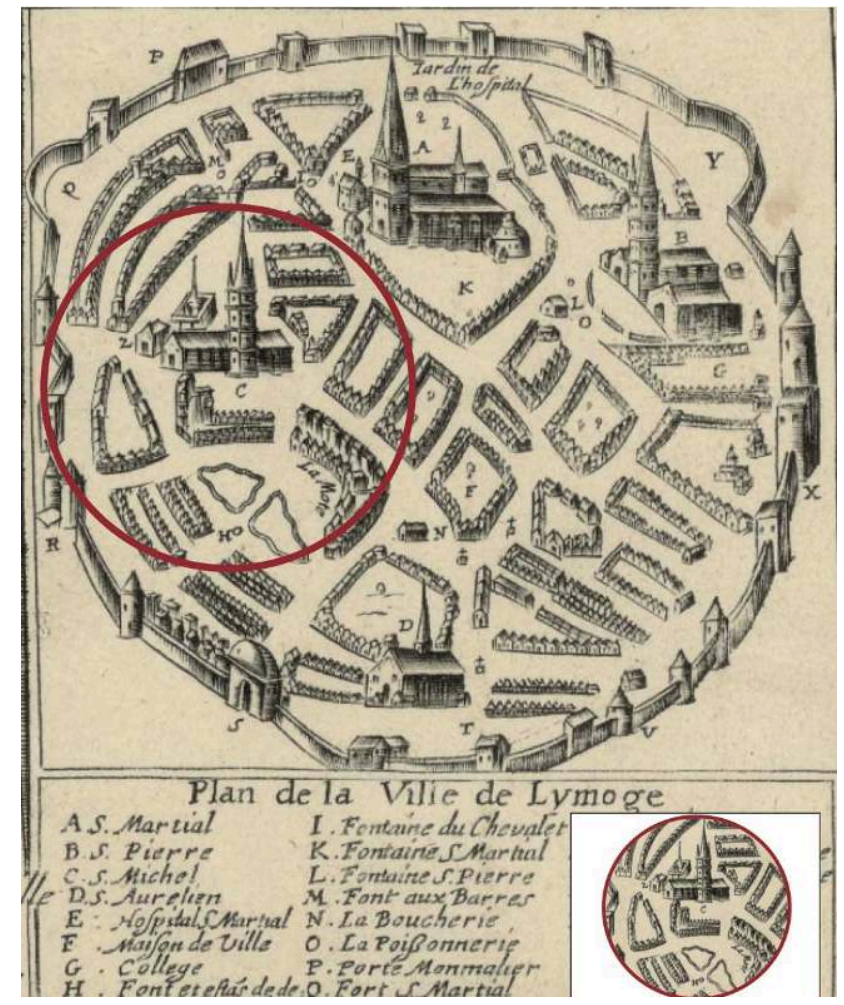

Plan de Limoges en 1594 : détail du palais de Justice et de la place du Présidial de Limoges, extrait de Totius Lemovici et confinium provinciaru quantum ad diocesin Lemovicensen, Jean Fayen, Édition N. Langlois, 1594

Reproduction https://catalogue.bnf.fr/ark:/12148/cb40695782p [lien valide en octobre 2021]. 


\section{L’ancien présidial}

8 À l'instar d'une trentaine d'agglomérations secondaires de province et en vertu de l'édit d'Henri II de janvier 1552, la ville de Limoges accueille un présidial, juridiction intermédiaire entre la sénéchaussée et le parlement de Bordeaux. Elle constitue une cour d'appel pour les contentieux civils et criminels de moindre importance afin d'alléger la procédure et la charge des affaires incombant aux parlements ${ }^{23}$. Incarnation de l'État dans les villes secondaires, l'institution procure également aux notables locaux des opportunités de carrière dans la magistrature ${ }^{24}$ et leur prestige est tel qu'ils chevauchent en tête de cortège avec les consuls de Limoges lors des processions urbaines.

Le choix d'implantation du présidial se porte sur une maison curiale attenante à l'église Saint-Michel-des-Lions: si l'on admet que la place du Belvédère constituait effectivement un lieu de justice à l'époque médiévale, la nouvelle institution s'inscrit alors dans une logique de continuité des usages. Elle offre également l'avantage d'un emplacement central et la proximité avec la tour du Breuil, siège de la sénéchaussée. Toutefois, le choix d'une simple demeure urbaine pour accueillir un édifice à vocation publique interpelle nos conceptions contemporaines des manifestations de l'État. Rappelons que la plupart des présidiaux ne furent pas mieux lotis : agrégés aux sièges des communes ou des sénéchaussées, les magistrats présidiaux ne disposaient souvent que de quelques pièces pour exercer leur office, lorsqu'ils n'étaient pas contraints au nomadisme $\mathrm{e}^{25}$. À Limoges, les vestiges archéologiques, confrontés aux sources historiques et iconographiques, livrent une esquisse sommaire du palais de justice. Le bâtiment était perpendiculaire à la nef de l'église Saint-Michel-des-Lions afin d'offrir aux desservants du culte un accès direct à l'église. Les arrachements de maçonnerie conservés dans le mur de l'église déterminent un bâtiment à trois niveaux, soit un rezde-chaussée, un étage équipé d'une cheminée et un niveau sous combles [fig. 4]. 


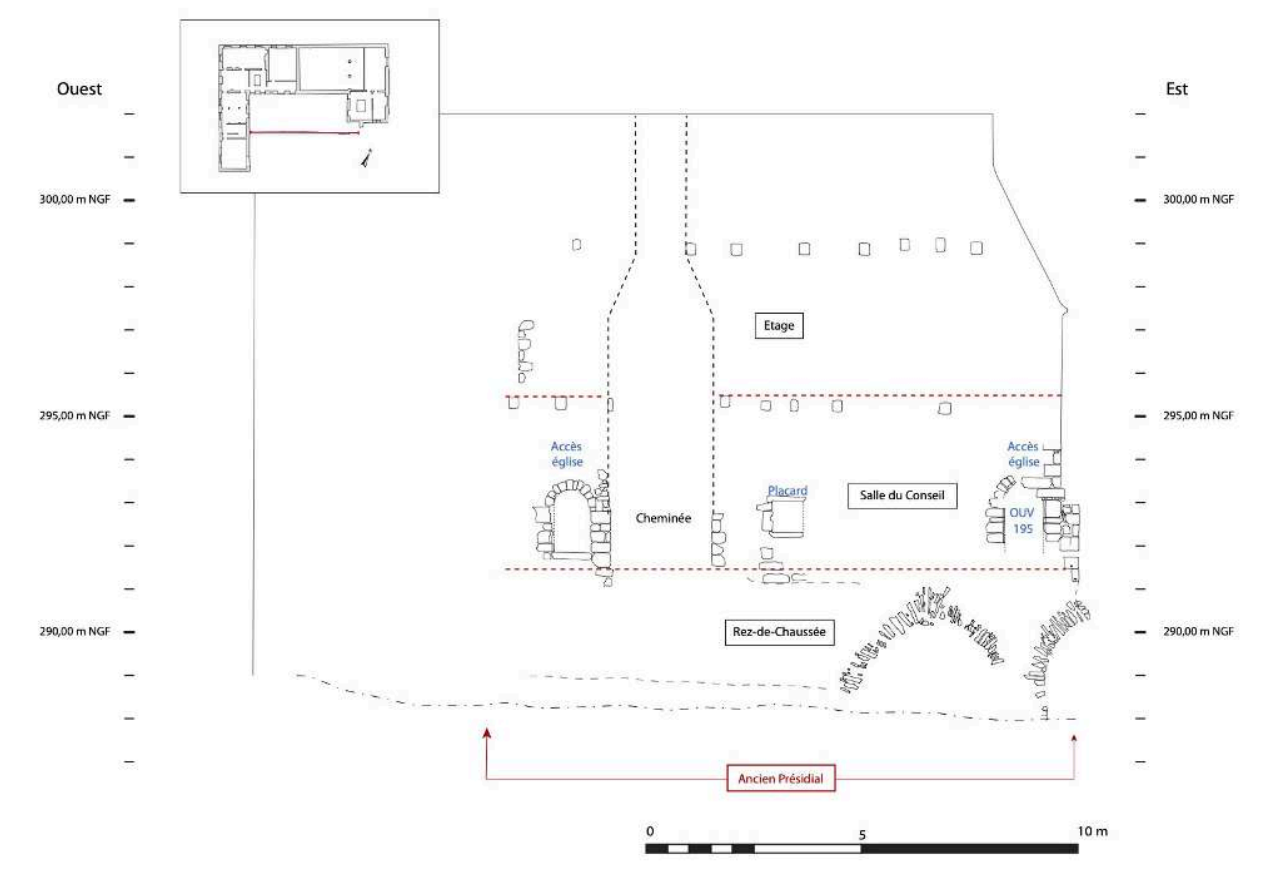

Essai de restitution des niveaux de l'ancien Présidial, 2019.

(c) Lasergrammétrie et photogrammétrie E. Balbo (Archéa) / @ DAO M. Canivet, L. Leroux (Hadès).

Un récit daté de 1589 offre quelques précisions supplémentaires : les portes du palais donnaient vraisemblablement sur la place du Belvédère et le rez-de-chaussée contenait également des cachots. À l'étage est localisée la salle du Conseil, où se réunissaient les magistrats. D'après les vestiges archéologiques, cette dernière présentait une hauteur de $3,75 \mathrm{~m}$ de hauteur sous plafond, et disposait d'une ample cheminée et de placards ainsi que d'accès vers l'église, permettant aux magistrats de suivre l'office depuis une tribune. Des blocs sculptés découverts dans les maçonneries du présidial du XVIII ${ }^{\mathrm{e}}$ siècle, relevant de l'architecture civile, et des soupçons de réemploi, laissent imaginer l'existence d'une colonnade, dont l'ordre toscan évoque la seconde moitié du xvi siècle ou le $\mathrm{XVII}^{\mathrm{e}}$ siècle. Un autre bloc indique la présence d'une corniche aux moulures classiques, entrant sans doute dans la composition de la façade. Ces fragments architecturaux constituent les seuls éléments d'ornementation qui peuvent être restitués de l'ancien présidial. De fait, l'investissement du décorum était laissé à la discrétion des magistrats ${ }^{26}$, d'abord par souci d'économie des finances royales, mais aussi en accord avec une autre conception de la dignité de l'institution, tenant d'abord à ses officiers et non à l'édifice. Les éléments de la colonnade, en partie réutilisés dans l'architecture du présidial du XVIII ${ }^{\mathrm{e}}$ siècle, évoquent toutefois une évolution essentielle de la justice à l'époque moderne, l'invention d'une sacralité propre au pouvoir judiciaire, distancié du jugement chrétien, et incarnant la conception du palais de justice comme un temple ${ }^{27}$.

11 Dans les années 1630 , lors des révoltes contre la gabelle, les insurgés s'attaquèrent au présidial, désormais clairement identifié en tant que représentation du pouvoir royal [fig. 5]. 
Figure 5

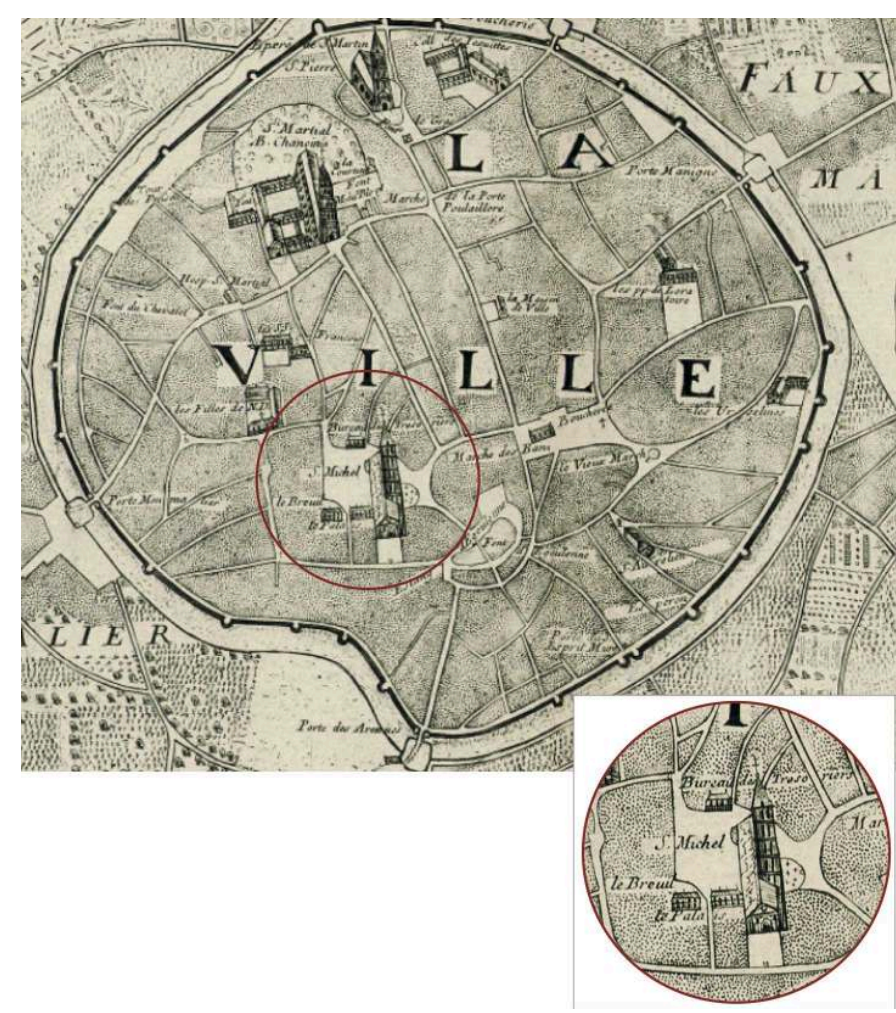

Plan de la ville de Limoges en 1676 : détail du palais de Justice et de la place du Présidial de Limoges, extrait de Limoges dédié à Mrs Les Presidens Tresoriers de France Generaux des Finances et Grands Voyers en la Generalite de Limoges Chevaliers Conseillers du Roy Juges et Directeurs du Domaine, A. Jouvin de Rochefort, 1676.

Reproduction https://gallica.bnf.fr/ark:/12148/btv1b5971852c.r=plan\%20limoges?rk=21459;2 [lien valide en octobre 2021]

Le récit d'un contemporain précise qu'ils incendièrent les prisons, laissant supposer que ces dernières étaient alors indépendantes du présidial, qui ne semble pas avoir connu de dommages lors de cet événement. Les prisons brûlèrent pendant près de douze heures, à tel point que «les grilles de fer qui étaient là tombèrent toutes par elles-mêmes » et les prisonniers n'eurent la vie sauve que grâce à l'intervention du voisinage $^{28}$. Afin de réaffirmer leur autorité mise à mal par cet incident, les magistrats présidiaux lancèrent immédiatement la reconstruction de la prison « depuis le creux de basses fosses jusques aux hauts de tuiles, le tout de pierre de tailles », une précaution indispensable pour prévenir les incendies, mais également toute tentative d'évasion. Ces investissements inédits consacrés à la durabilité et à la monumentalité du bâtiment dénotent un souci accru des lieux d'incarcération au XVII siècle, afin de préserver l'ordre public et de faire respecter la procédure judiciaire, dont l'alourdissement occasionnait des durées d'emprisonnement de plus en plus longues en attente de jugement ou d'appel. Le siècle du "Grand Enfermement " fut également celui des confréries d'assistance aux prisonniers ${ }^{29}$ : à Limoges, apparaît en 1660 la confrérie des Pénitents pourpres qui, entre autres actes de bienfaisance, accompagnait les condamnés jusqu'à l'échafaud et leur donnait sépulture dans un ancien cimetière de pestiférés ${ }^{30}$.

Les précautions des magistrats n'empêchèrent pas de nouvelles évasions au cours du siècle suivant, en raison de l'implantation des prisons contre l'une des chapelles de 
l'église Saint-Michel ${ }^{31}$. Sans doute le terrain manquait-il pour assurer l'isolement de la prison : en cœur de ville, l'habitat était dense et l'existence d'anciennes caves atteste de la présence de demeures voisines, sinon mitoyennes, du présidial.

$\mathrm{Au}$ milieu du XVIII ${ }^{\mathrm{e}}$ siècle, le présidial était si délabré que ses magistrats l'abandonnèrent en faveur du bâtiment de la trésorerie, situé en vis-à-vis, cohabitant avec «ces messieurs des finances». Les prisons étaient encore en usage mais en conséquence de l'évasion réussie depuis l'église Saint-Michel, elles se trouvaient dans les années 1770 dans un petit bâtiment de plan carré, donnant sur la bien-nommée rue des Prisons. Un mur de refend paraît définir un cachot exigu et obscur [fig. 6]. Les prisons étaient alors «dans un tel état de vétusté que les prisonniers pourraient être écrasés par leurs ruines $^{32}$ ». Il fallut attendre le dynamisme d'intendants de la généralité de Limoges, Anne Robert Jacques Turgot d'abord puis Nicolas Daine, pour que s'amorce la reconstruction du présidial, décrétée par le Conseil du roi.

Figure 6

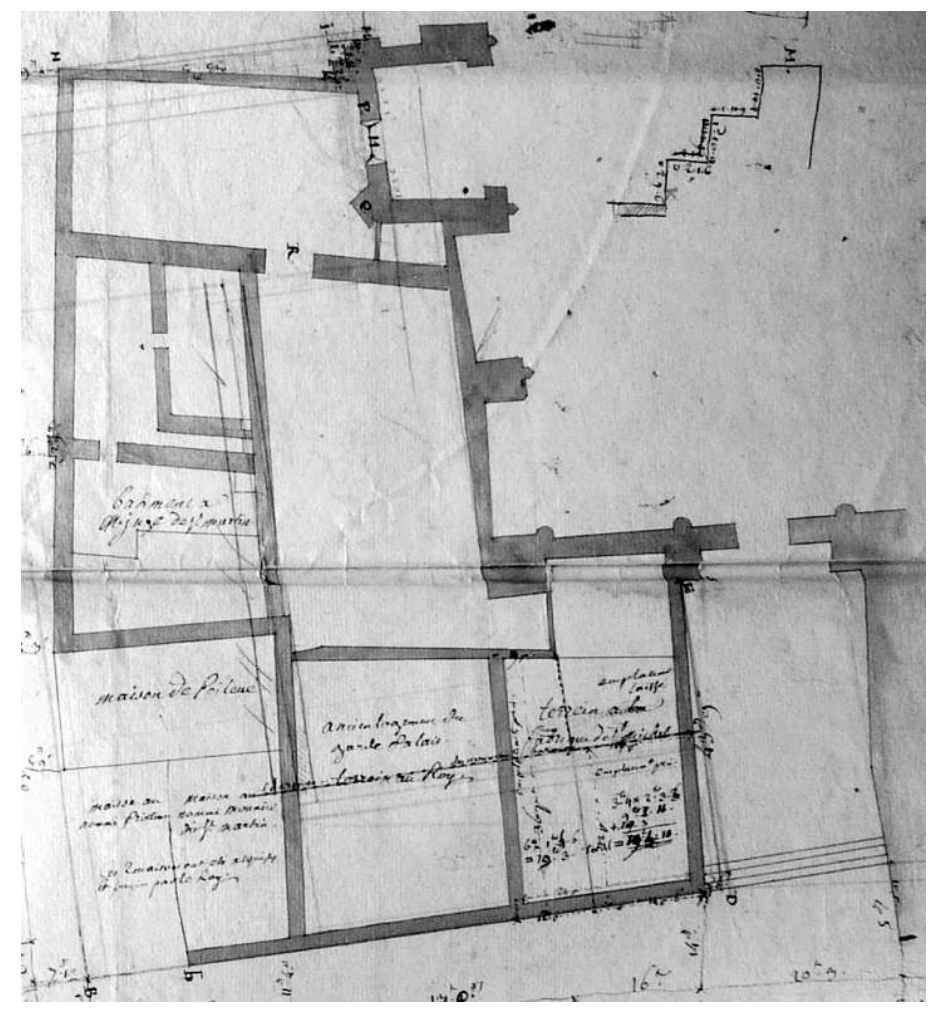

Plan de l'ancien Présidial dressé en 1777 avant sa destruction par l'ingénieur Cadié, conservé aux archives départementales de la Haute-Vienne (C 673)

Reproduction Claire Gravelat.

\section{Le présidial d'Ancien Régime, un édifice exemplaire?}

La ruine du présidial de Limoges ne constitue pas un cas isolé dans la France du $\mathrm{xVIII}^{\mathrm{e}}$ siècle; dès le XVII ${ }^{\mathrm{e}}$ siècle, faute de finances, ces bâtiments périclitaient dans un cadre qui s'était souvent révélé impropre, dès l'origine, à l'exercice de leur activité. S'ajoute à ce constat la dénonciation réitérée des conditions d'incarcération, d'autant plus injuste que l'emprisonnement concernait majoritairement des justiciables en 
attente de leur procès. Entre 1765 et 1785, furent effectuées sur ordre du roi de nombreuses enquêtes sur les prisons de tout le royaume, qui révélèrent l'impossible secret de la procédure judiciaire ainsi qu'une promiscuité et une insalubrité qui choquèrent une opinion publique sensibilisée à ces problématiques par les idées hygiénistes diffusées par les Lumières ${ }^{33}$. Les architectes s'emparèrent alors de cette problématique: dès les années 1750, Jacques-François Blondel (1705-1774) imagine diverses typologies de prisons tandis que l'Académie royale d'architecture en fait l'objet de concours dans les années $1760-1780^{34}$ et l'architecte Nicolas Ledoux (1736-1806) conçoit un projet ambitieux pour la municipalité d'Aix-en-Provence en 1785, toutefois jamais réalisé ${ }^{35}$. Le présidial de Limoges est l'une des rares manifestations abouties de cette volonté réformatrice.

\section{Le projet}

La reconstruction du présidial est confiée à un ingénieur des Ponts et Chaussées dénommé Cadié, et pour le guider dans son projet, le lieutenant général de Limoges énonce plusieurs préconisations quant au « détail des pièces nécessaires tant pour les prisons que pour un palais ${ }^{36} »$. Outre la prévention des évasions, la conception du plan de l'édifice doit prendre en considération le secret de l'instruction: il faut donc privilégier la démultiplication de petites cellules voûtées et isolées de la rue pour éviter toute entente des prisonniers entre eux ou avec l'extérieur. Pour maintenir la discipline, doit également être prévue une "prison noire" d'une capacité de quatre personnes. À l'entrée des prisons, communiquant avec les cachots, doit se situer un guichet où s'effectueront les dépositions. Des prisons civiles seront aménagées dans les étages, sous forme de chambres d'une capacité de six personnes, dont certaines disposeront de cheminées, en fonction du statut social des prisonniers. La salubrité des lieux n'est pas exempte des dispositions prévues : les cellules devront être équipées de latrines et leurs portes d'un bas-jour permettant la circulation de l'air ; un préau est également exigé pour laisser sortir les prisonniers. Aux étages, outre les latrines, les prisonniers civils auront accès à une chapelle et à une pièce commune pour les repas et la distribution des aumônes. Pour le palais de justice, son entrée doit s'effectuer depuis la place, dite alors Saint-Michel. Il doit comprendre une salle des parties, destinée à accueillir les procureurs, avocats et leurs clients, précédant la salle d'audience. Cette dernière doit intégrer une estrade surélevée à l'angle de la pièce, où siégeront les juges, et le barreau en vis-à-vis, auxquels s'ajouteront trois rangs de bancs pour accueillir l'assistance, l'ensemble constituant le parquet de justice. Dans la salle d'audience doit également être aménagée une chapelle, sous forme d'une tribune. Il est requis que les juges pourront disposer d'un accès privatif à la salle d'audience, desservant également la salle du Conseil, où les juges délibèrent. Au voisinage immédiat de cette salle se situeront les pièces à l'usage du parquet et des huissiers. Outre ces dispositions très précises, le lieutenant général énumère l'ensemble des pièces requises pour le fonctionnement du présidial: à proximité des prisons, deux pièces disposant de cheminées pour les instructions de la prévôté et du lieutenant criminel, ainsi qu'une chambre de torture, auxquelles s'ajoutent le bureau du greffe et son dépôt d'archives, de même qu'un dépôt des minutes des notaires, une buvette et enfin le logement du garde du palais. Le lieutenant général recommande également d'intégrer au futur bâtiment le bureau des finances et l'hôtel de ville, alors en ruine. 
À partir de ce cahier des charges très détaillé, Cadié soumet aux maîtres d'ouvrage un projet décrivant les formes et dimensions générales du bâtiment, conjugué à des plans préparatoires. Malgré la gêne que constitue le voisinage de l'église, il reconnait les avantages que procurent la présence d'une place publique, la proximité des autres institutions et la possession de ces terrains par le roi. Outre la démolition complète de l'ancien présidial, il juge nécessaire l'acquisition des parcelles voisines afin de donner au nouvel édifice l'ampleur que requièrent les exigences du lieutenant général. Il prévoit en outre de remodeler la topographie de la place pour en réduire le relief et s'attache à inscrire l'édifice dans un plan orthonormé et cohérent avec le plan d'alignement des rues engagé à partir de 1775. Cette refonte urbaine, tant topographique que parcellaire, constitue un préalable indispensable à la réalisation de ses ambitions architecturales. L'ensemble sera constitué de deux bâtiments contigus, le présidial, donnant sur la place, et les prisons civiles, donnant sur la rue des Fossés, le tout organisé en trois ailes autour d'une cour, close au sud par l'église Saint-Micheldes-Lions. Dans les soubassements du présidial sont prévues les prisons présidiales et criminelles, dont trois cachots noirs, ainsi que la chambre de question et les dépendances. Le rez-de-chaussée est subdivisé entre la salle des parties, l'audience et la salle du Conseil, tandis que l'étage sera dédié aux Finances [fig. 7]. Dans le second bâtiment, le rez-de-chaussée, donnant sur la rue, sera dévolu au guichet et au logement du concierge. À l'étage, dix chambres, à raison de 20 à 25 lits, constitueront les prisons civiles, desservies par un corridor.

\section{Figure 7}

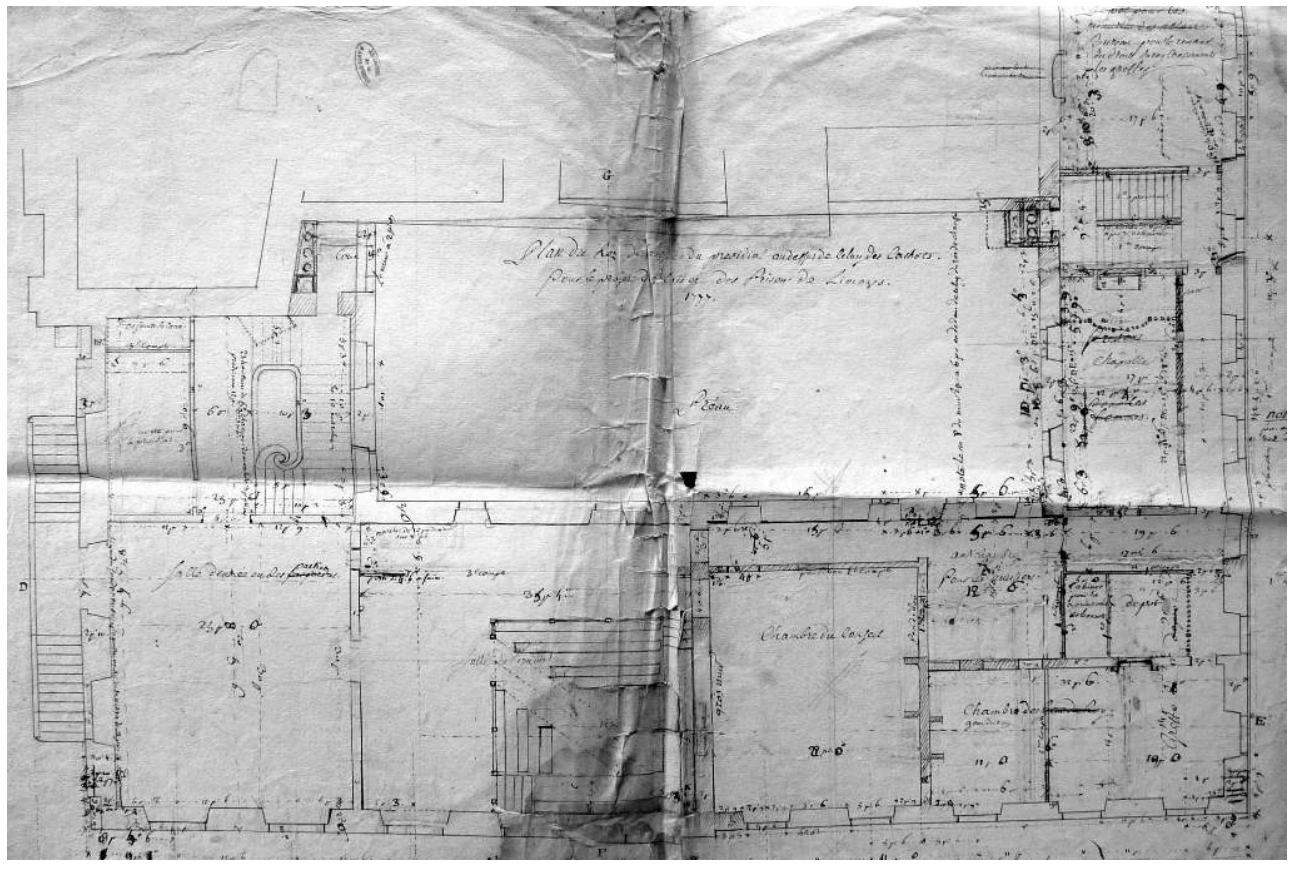

Projet du Palais et des prisons de Limoges, rez-de-chaussée, conservé aux archives départementales de la Haute-Vienne (C 673).

Reproduction Claire Gravelat.

Les magistrats présidiaux adhèrent au projet, non sans quelques préconisations supplémentaires relevant essentiellement de considérations pratiques et de respect des usages locaux, notamment envers les Pénitents rouges. Les chambres criminelles et 
prévôtales doivent intégrer un cabinet pour servir de dépôt aux effets des inculpés "qui servent quelquefois de pièces de conviction ». Des recommandations concernent également la distribution et notamment, l'aménagement d'un corridor permettant de gagner la salle du Conseil ou les chambres des greffes et des huissiers sans traverser l'audience. En revanche, les magistrats, attachés à leurs bancs ecclésiaux dans l'église Saint-Michel ${ }^{37}$, jugent la création d'une chapelle superflue et plaident la cause de leurs collègues des Finances pour l'agrandissement des salles de l'étage en renonçant à l'accueil d'une autre juridiction.

\section{La réalisation}

Le chantier démarre en 1777 : prévu pour deux ans, il en durera le double, notamment en raison de la découverte inattendue de multiples caves, qui se répartissent parfois sur trois niveaux superposés. Si ces ouvrages souterrains constituent une contrainte, l'ingénieur Cadié en tire parti pour y aménager des latrines à disposition des prisonniers [fig. 8].

Figure 8

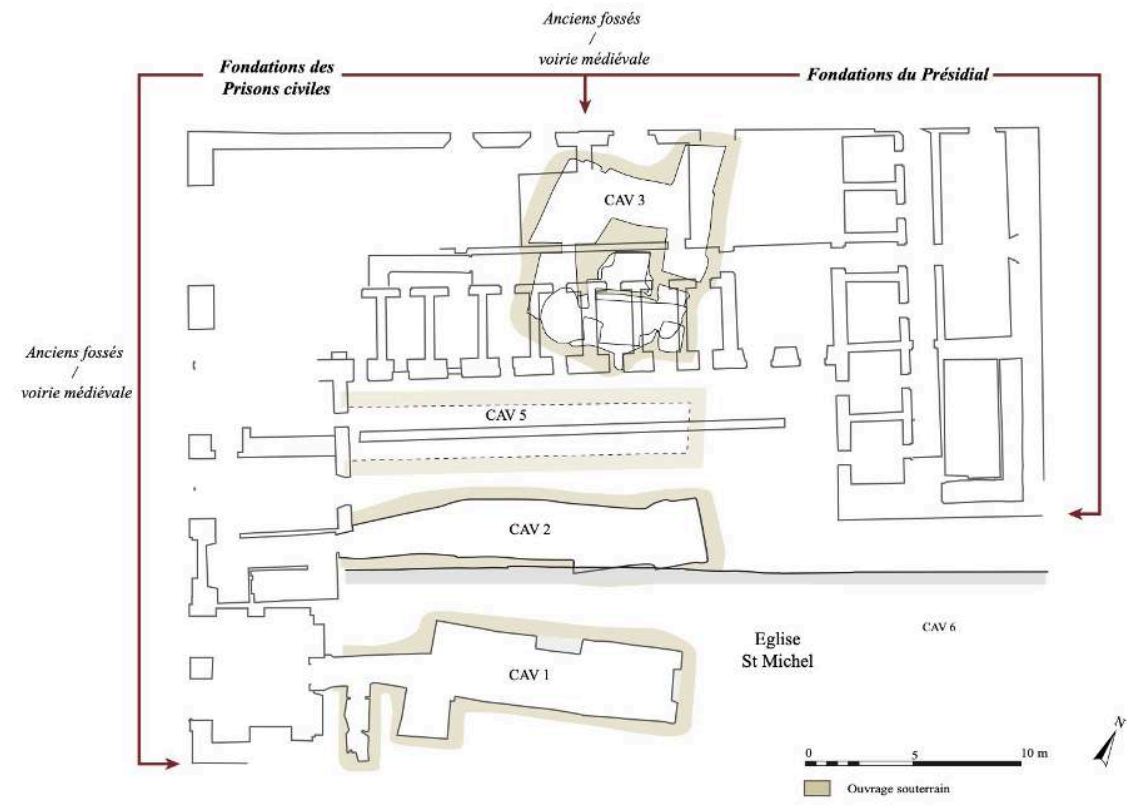

Plan des ouvrages souterrains sur les parcelles du Présidial, 2019.

(c) Lasergrammétrie et photogrammétrie E. Balbo (Archéa) / ( c DAO M. Canivet, L. Leroux (Hadès)

En raison de la topographie du site, le bâtiment du présidial est construit en déblai, enterrant partiellement le soubassement éclairé par deux soupiraux qui entre dans la composition de la façade. La volumétrie du bâtiment surélève l'entrée du présidial, hors d'atteinte du commun hormis par un perron à double volée, autant de composants scénographiques d'un itinéraire initiatique vers le lieu de justice ${ }^{38}$. La façade, sévère et imposante, est agencée selon un ordonnancement classique de travées rythmées par des pilastres, en grand appareil de granit dont les blocs sont mis en exergue par des joints en refend, soulignant les chaînes des linteaux à crossettes, l'ensemble constituant 
un bel exemple d'architecture parlante. Un fronton accusant les rampants du toit couronne l'élévation, timbré d'armoiries fleurdelisées en son centre, en rappel écrasant de l'autorité royale. L'élévation en retour sur la rue des Prisons est plus sobre encore, seulement animée par les corniches filant depuis la façade, et dont l'enduit ne laisse émerger que les chaînes d'angle. Dans les soubassements du présidial, les prisons criminelles et prévôtales sont constituées de treize cellules dont la superficie ne dépasse pas 5,5 $\mathrm{m}^{2}$ [fig. 9] et donnant exclusivement sur la cour au moyen de baies surélevées et munies de lourdes grilles. Voûtées, leurs murs sont maçonnés en grand appareil de pierre taillée, de même que les sols, afin de réduire les joints et la possibilité de descellement des blocs [fig. 10]. Elles sont fermées de lourdes portes, qui ne peuvent être ouvertes que depuis le corridor. Par la suite, les cellules semblent avoir été équipées de « lits mobiles », des couchettes rabattables et surélevées pour préserver les prisonniers des nuisibles et de l'humidité du sol ${ }^{39}$ [fig. 11]. Outre ces cellules, les soubassements comprennent la salle de la question et les chambres d'instruction, côté rue, ainsi que de vastes caves [fig. 12].

Figure 9

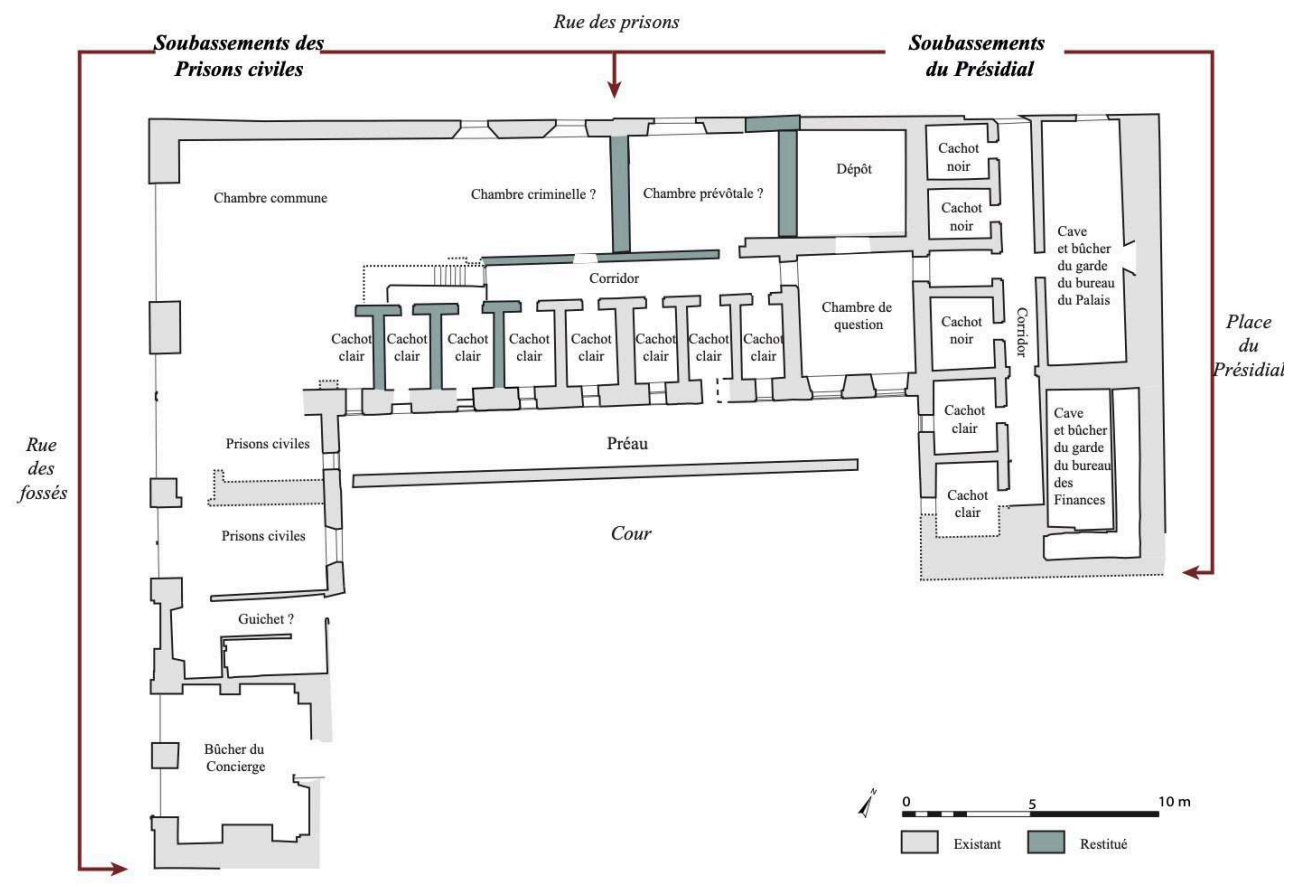

Essai de restitution des espaces du Présidial, soubassement, 2019.

(c) Lasergrammétrie et photogrammétrie E. Balbo (Archéa) / @ DAO M. Canivet, L. Leroux (Hadès). 
Figure 10

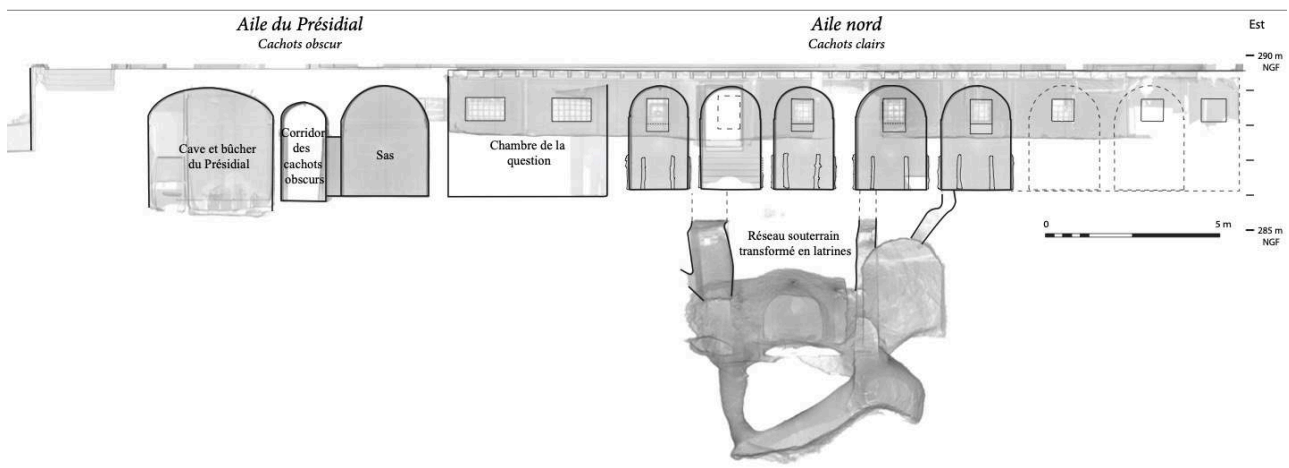

Coupe des cellules de l'aile nord du Présidial, 2019.

(c) Lasergrammétrie et photogrammétrie E. Balbo (Archéa) / @ DAO M. Canivet, L. Leroux (Hadès).

Figure 11

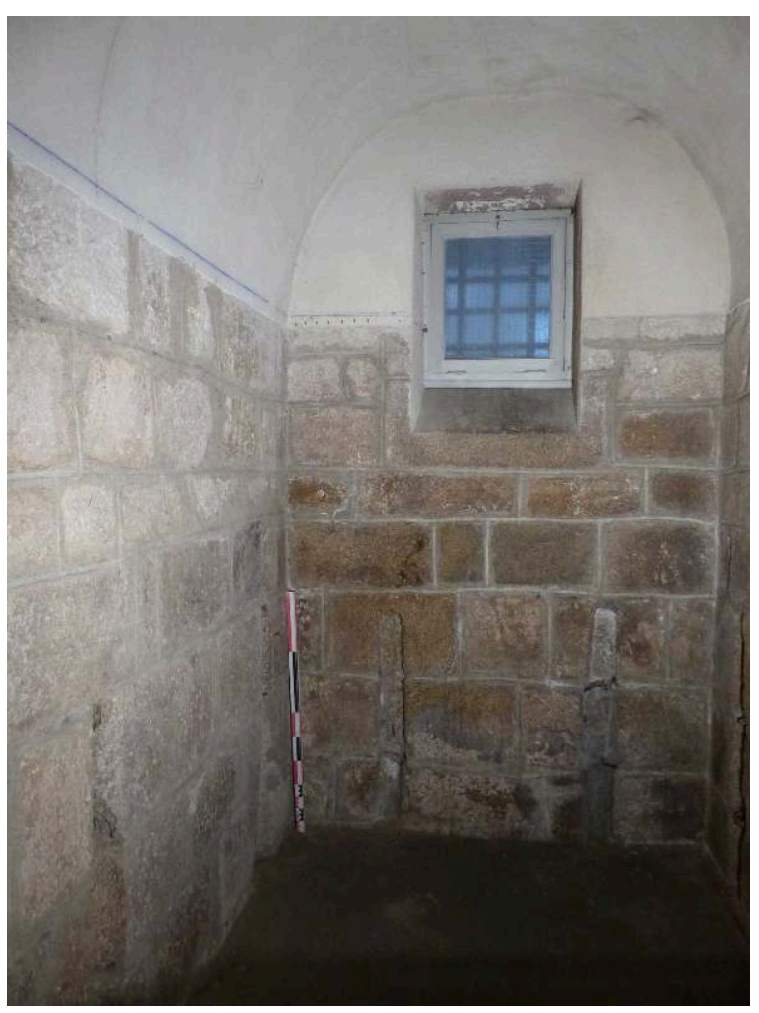

Vue d'une cellule de l'aile nord du Présidial, 2019.

(c) L. Leroux (Hadès). 
Figure 12

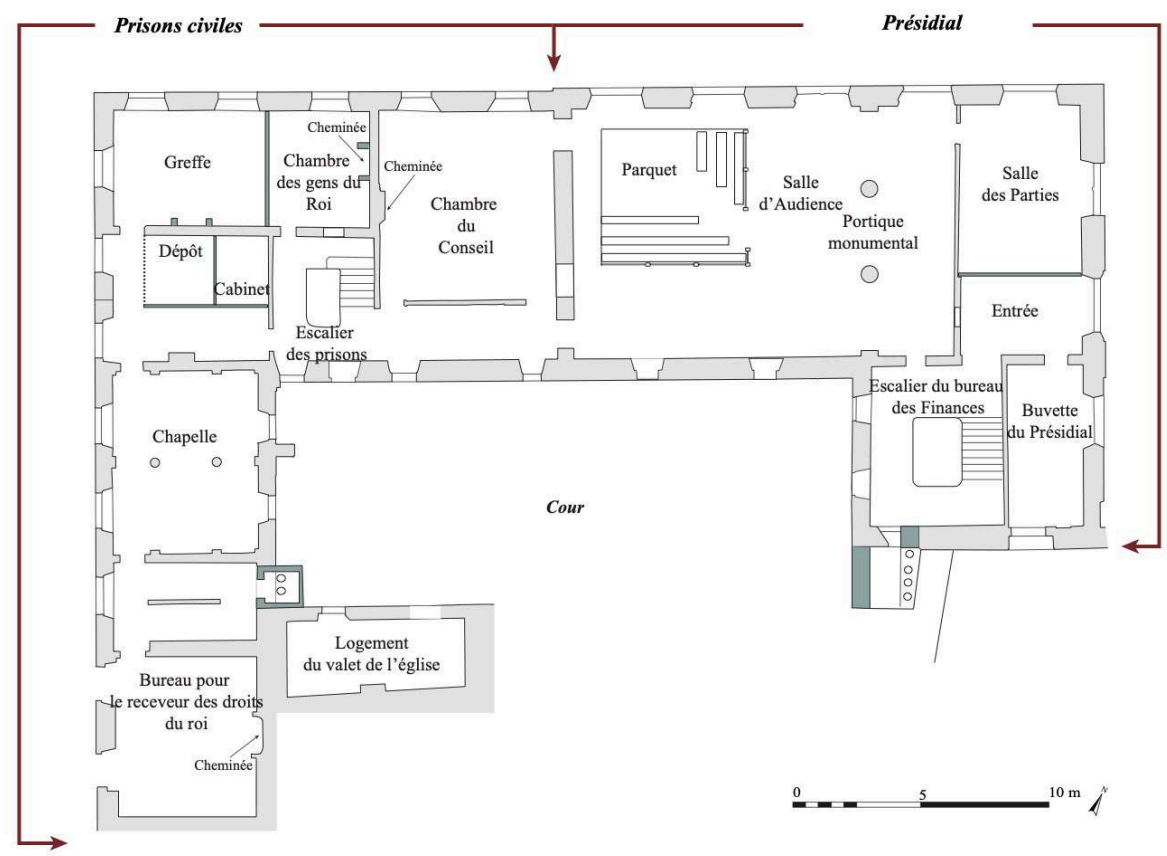

Essai de restitution des espaces du Présidial, rez-de-chaussée, 2019.

(c) Lasergrammétrie et photogrammétrie E. Balbo (Archéa) / @ DAO M. Canivet, L. Leroux (Hadès)

21 Le niveau dédié au présidial s'ouvre sur la salle des pas perdus à main droite, sous la surveillance du garde du palais [fig. 13]. 
Figure 13

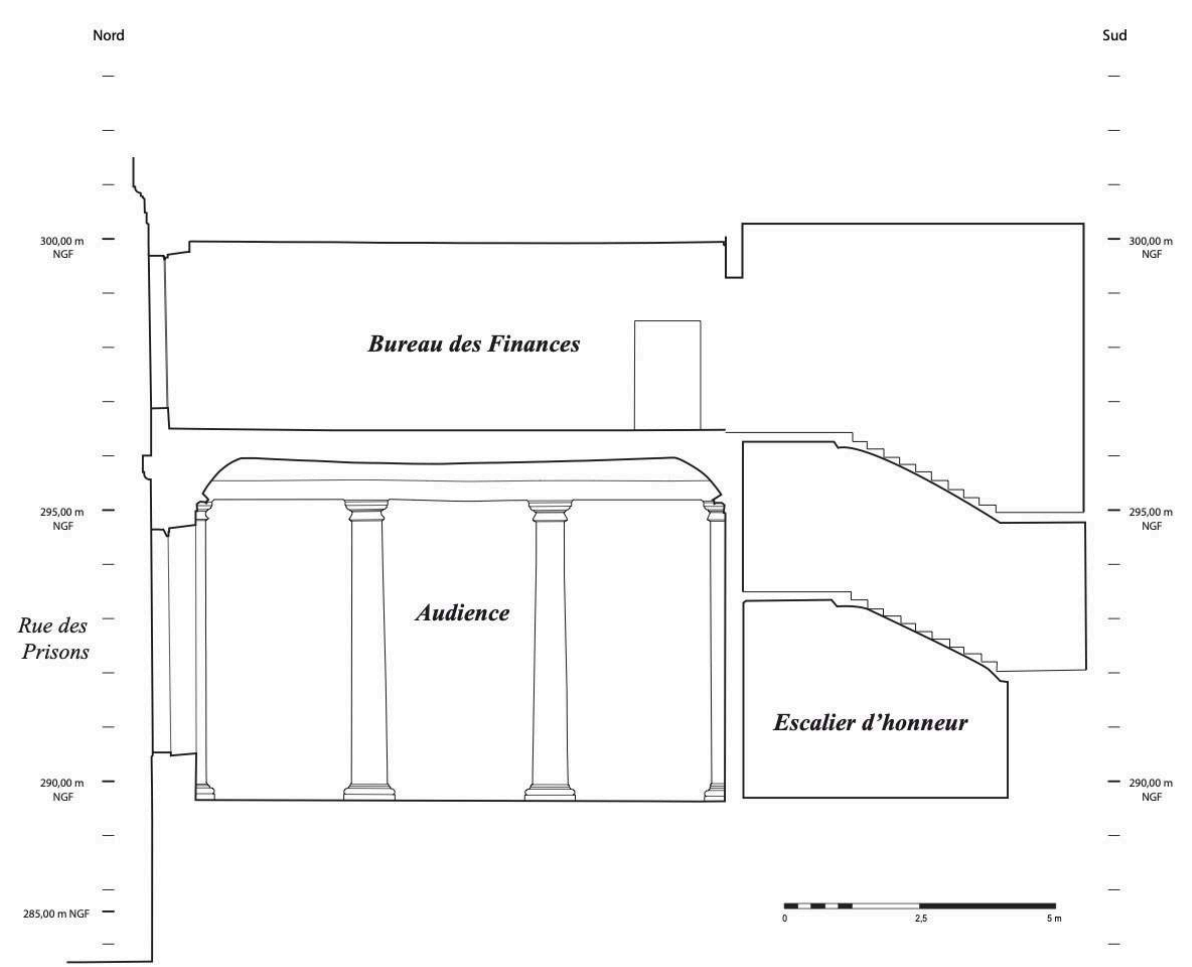

Coupe de la salle de l'audience et de l'escalier d'honneur, 2019.

(c) Lasergrammétrie et photogrammétrie E. Balbo (Archéa) / (c DAO M. Canivet, L. Leroux (Hadès).

L'accès au parquet, dans la salle d'audience, impose aux parties le passage par une colonnade constituée de deux colonnes et deux pilastres, de $6 \mathrm{~m}$ de hauteur sous plafond, qui forme un portique monumental manifestant la solennité du lieu [fig. 14]. Cette réalisation spectaculaire, absente des plans de l'ingénieur Cadié, peut avoir été commanditée par les magistrats afin d'incarner le temple de la justice. Conformément aux requêtes des magistrats, les juges peuvent gagner la salle du Conseil depuis l'audience, par un long corridor permettant de circuler sans troubler les débats judiciaires. Suite à la construction du second bâtiment, ce corridor donne accès à l'escalier menant aux prisons présidiales et prévôtales. Un autre escalier, nettement plus monumental, à volées suspendues, dans le goût du XVIII ${ }^{\mathrm{e}}$ siècle, se situe à proximité de l'entrée et fait honneur à l'étage des officiers des Finances. Les occupations ultérieures n'ont guère laissé de vestiges des décors originels : quelques moulures en stuc des cheminées, des enduits peints en faux appareil ou les négatifs de boiseries autour des portes, et notamment des attiques, que réclamaient les magistrats. 


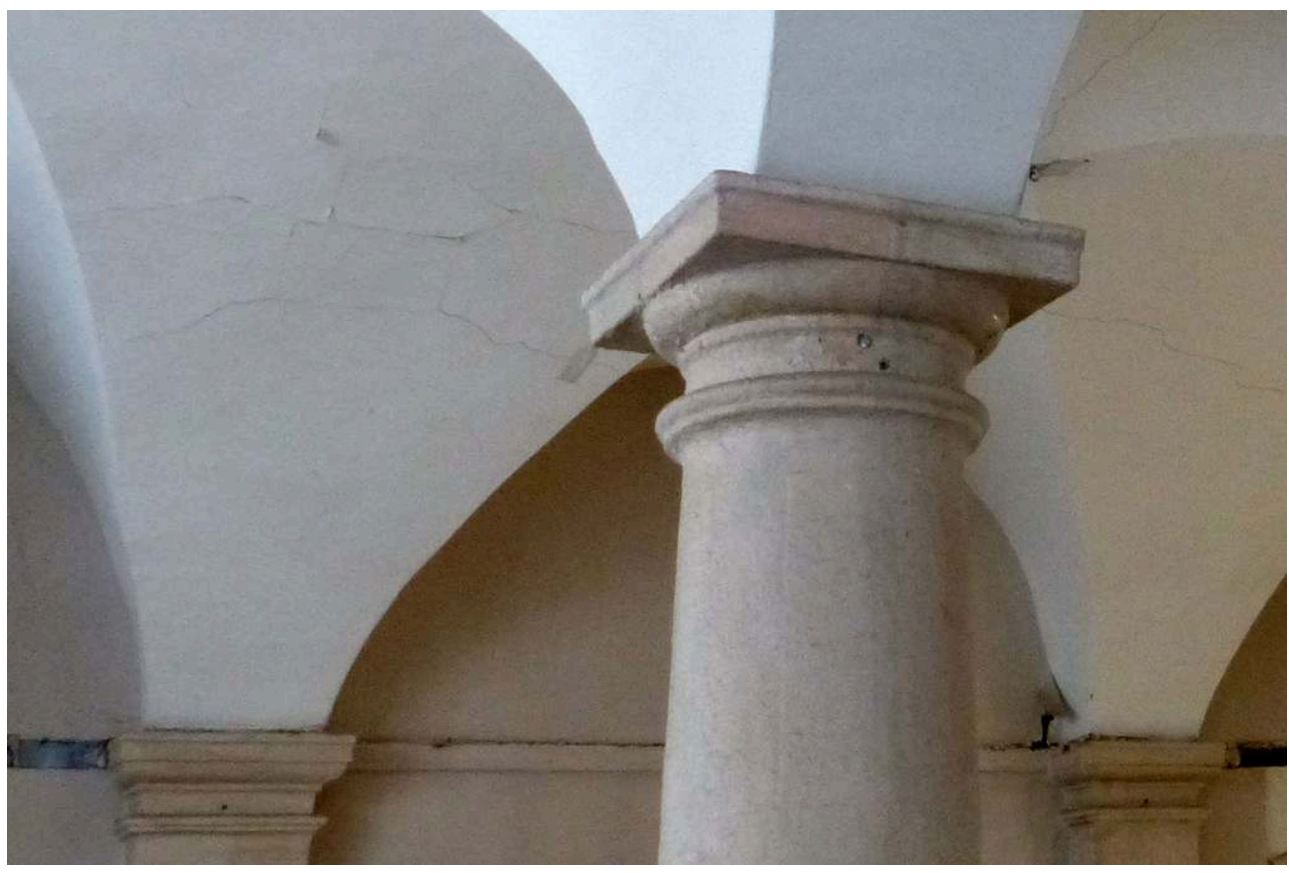

Vue des colonnes de la chapelle de l'aile orientale, 2019.

(C) L. Leroux (Hadès).

L'analyse archéologique indique que le bâtiment des prisons civiles fut réalisé dans un second temps (figure 9 et 12) et que la qualité de la construction se ressentit des retards du chantier et de l'accumulation des difficultés financières, introduisant plusieurs modifications par rapport au plan initial. L'accès s'effectuait par la rue des Fossés, l'une des principales artères de la ville, et dès l'entrée, à main gauche, se trouvait le guichet, prolongé par un corridor desservant deux cachots de 15 et $20 \mathrm{~m}^{2}$ de superficie. À main droite devait se situer la chambre des valets, tandis que le concierge était logé dans une petite habitation indépendante dominant le préau. Au premier étage, initialement dévolu à la prison des femmes, était aménagée une chapelle dont les voûtes d'arêtes retombent sur des colonnes et des pilastres d'ordre toscan qui pourraient être des réemplois. Dans le mur nord, de grandes ouvertures permettaient aux prisonniers rassemblés dans la cour de suivre l'office. Au-dessus de la chapelle, une vaste pièce, subdivisée en deux travées par deux colonnes toscanes, pourrait correspondre à la salle commune voulue par les magistrats [fig. 15]. Un demi-niveau accueillait les chambres servant de prisons, d'environ $30 \mathrm{~m}^{2}$ de superficie. À l'origine, ce second bâtiment ne devait pas s'élever aussi haut que le présidial afin de signifier la hiérarchie des justices mais au cours du chantier ou lors d'autres travaux, un étage supplémentaire fut toutefois aménagé, sans doute afin d'accueillir les cellules des femmes, la promiscuité entre les genres choquant l'opinion publique [fig. 16]. Il faut encore ajouter à cette énumération une pièce pour les titres du roi ou pour les minutes des notaires. De cette démultiplication des espaces se dégagent l'impression d'une fourmilière administrative coexistant avec les lieux d'incarcération et la scénographie de l'exercice de la justice, selon une polysémie tout à fait saisissante. 
Figure 15

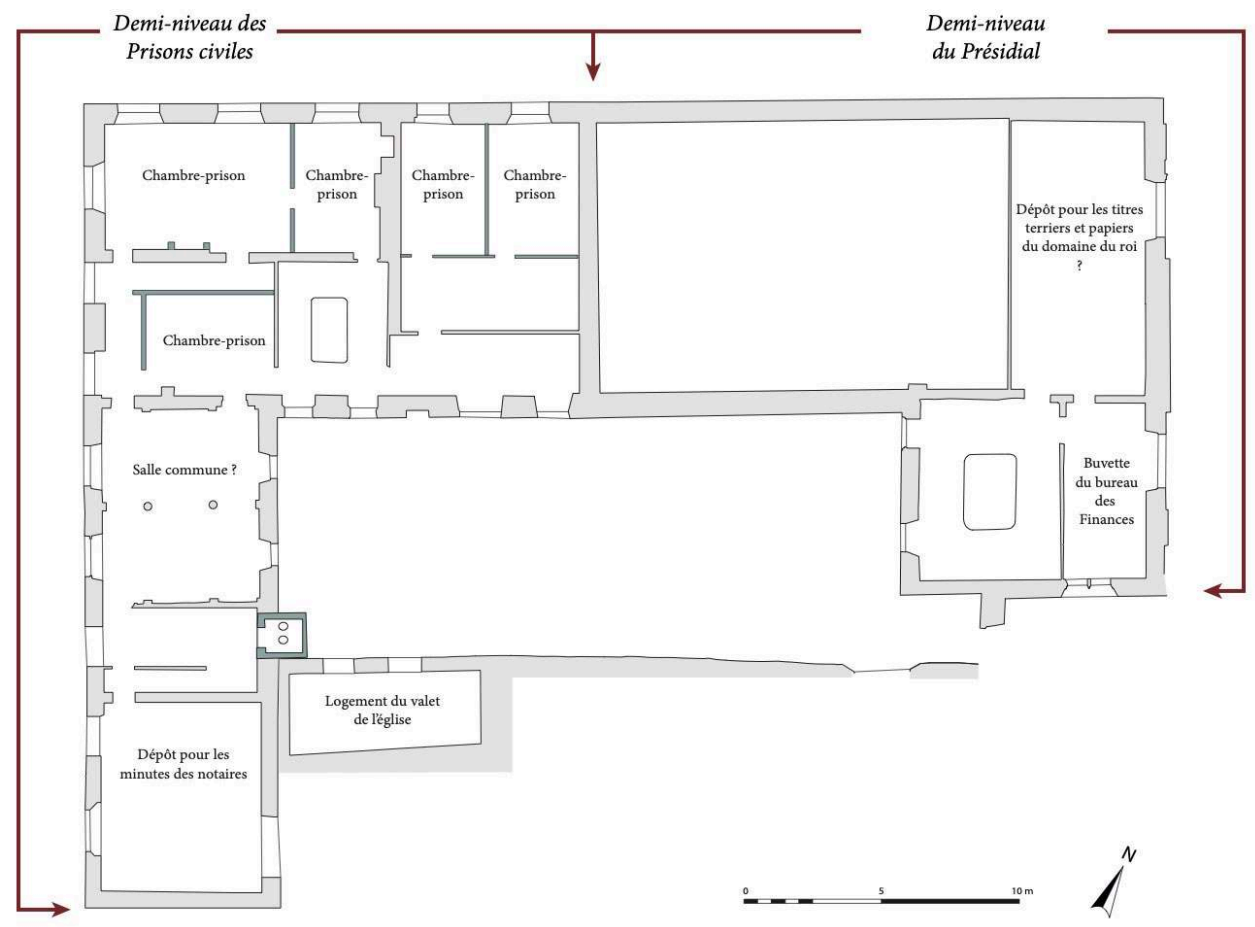

Essai de restitution des espaces du Présidial, entresol, 2019

(c) Lasergrammétrie et photogrammétrie E. Balbo (Archéa) / (c DAO M. Canivet, L. Leroux (Hadès).

Figure 16

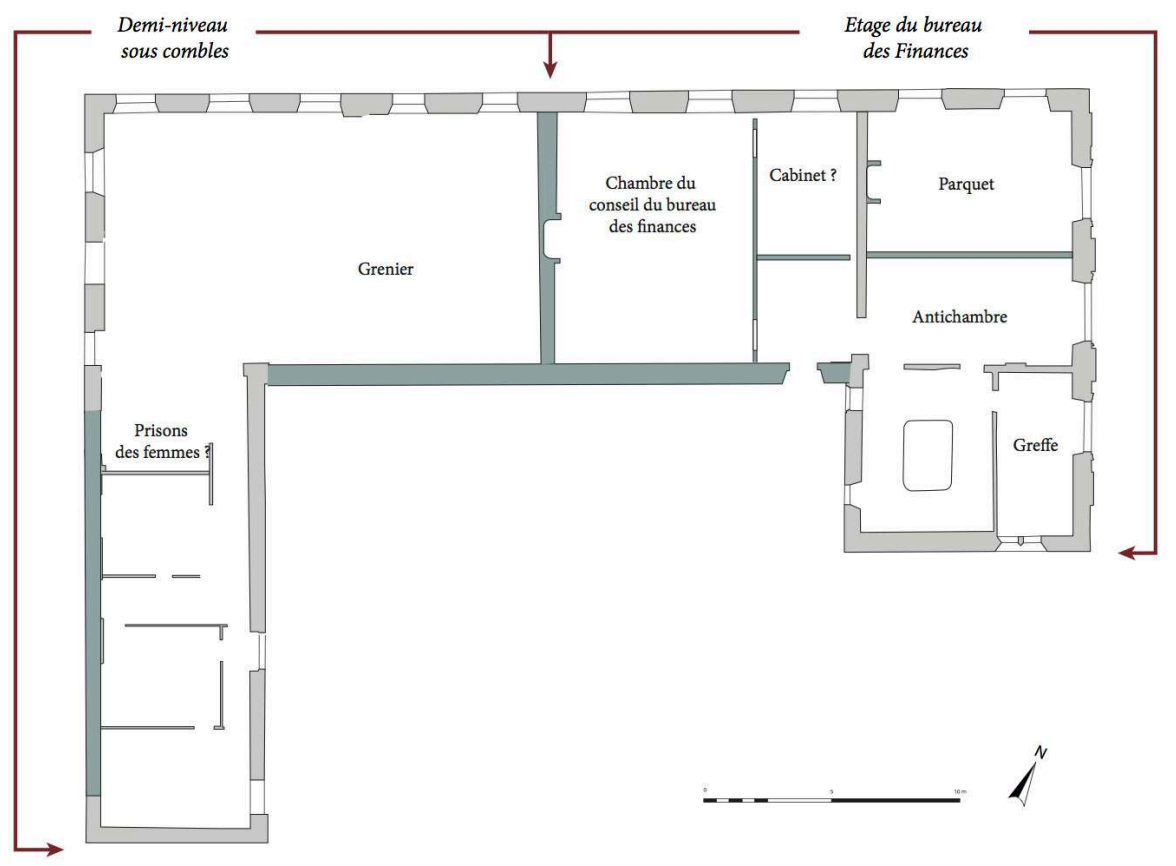

Essai de restitution des espaces du Présidial, étage, 2019.

(c) Lasergrammétrie et photogrammétrie E. Balbo (Archéa) / @ DAO M. Canivet, L. Leroux (Hadès). 
aration du présidial eut lieu le 18 novembre 1782 : le président du présidial loua un «édifice beaucoup plus vaste et plus somptueux que ne l'était le vieux temple de Thémis $^{40}$ ». Si les magistrats présidiaux ne l'occupèrent guère, du fait de la fin de l'Ancien Régime, l'édifice conserva son rôle de cour d'appel et de prison civile, ainsi qu'en témoigne un des rares graffitis découvert dans une cellule, daté de 1814. Après l'achèvement du palais de justice de la place d'Aisne, il fut employé à divers usages, avant d'accueillir, à partir de la fin du XIX ${ }^{\mathrm{e}}$ siècle, la faculté de droit.

L'édifice, fruit d'une collaboration entre l'ingénieur et les magistrats, s'il connut des modifications en cours de projet, constitue un monument d'architecture judiciaire, donnant à voir une symbiose étroite entre une architecture parlante et une conception rationnelle au service de ses nombreux usages. S'il n'est guère inscrit dans l'histoire de l'architecture, sans doute en raison de son aspect sévère, accentué par l'usage du granit local, le présidial de Limoges constitue pourtant l'une des rares incarnations de la volonté de réforme judiciaire qui anima l'État royal dans la seconde moitié du XVIII ${ }^{e}$ siècle. L'édifice est d'autant plus exemplaire qu'il fut conçu en collaboration avec ceux qui étaient destinés à l'occuper afin de faciliter leur adhésion au projet et qu'il s'inscrivait dans la continuité de l'histoire de la ville. À l'instar du parquet de justice figurant dans la cartographie urbaine $\mathrm{du} \mathrm{xVI}^{\mathrm{e}}$ siècle, le présidial incarnait l'un des composants essentiels du paysage monumental de Limoges.

\section{NOTES}

1. Voir https://www.pop.culture.gouv.fr/notice/merimee/PA00100379 [lien valide en novembre 2021].

2. Voir https://www.hades-archeologie.com/ [lien valide en novembre 2021].

3. Voir http://archea.net/ [lien valide en novembre 2021].

4. BALBO Éric, Recueil documentaire sur les cavités de l'Ancien Présidial, Limoges, Archéa, 2016.

5. VIVAS Mathieu (dir.), (Re)lecture archéologique de la justice en Europe médiévale et moderne, actes du colloque international organisé par Mathieu Vivas (Bordeaux, 8-10 février 2017), Bordeaux, Ausonius, coll. « Scripta Mediaevalia », 2019.

6. LEROUX Laure, avec la collaboration de BALBO Éric, Le Présidial. Limoges (Haute-Vienne). Rapport final d'opération, Limoges, SRA Nouvelle-Aquitaine, 2020.

7. GUYOT d'AMFREVILLE Pierre-Alexandre-Ferdinand-Olivier, La Vie et les œuvres de M.Juge de La Borie, avocat du Roi au siège présidial et sénéchal et premier maire de Limoges (1702-1779), Limoges, Vve H. Ducourtieux éditeur, 1877; PIRONNEAU Antoine-Louis-Auguste, Le Siège présidial de Limoges aux XVI et XVII'siècles, Limoges, Vve H. Ducourtieux éditeur, 1895.

8. DUCOURTIEUX Paul, Limoges d'après ses anciens plans, Limoges, Vve H. Ducourtieux éditeur, 1884, disponible en ligne https://gallica.bnf.fr/ark:/12148/bpt6k141994t.image [lien valide en novembre 2021].

9. DELAGE François, "Le Présidial de Limoges en 1688 », Bulletin de la Société archéologique et historique du Limousin, vol. LXXXIX, 1940, p.112-114. Résumé de la communication de Pascal Texier à la Société historique et archéologique du Limousin : TEXIER Pascal, « L'hôtel du Présidial à Limoges », Bulletin de la Société archéologique et historique du Limousin, vol. CXVI, 1989, p. 220-221. 
10. CASSAN Michel, "L'activité du Présidial de Limoges (fin XVII ${ }^{\mathrm{e}}$ siècle-fin XVIII ${ }^{\mathrm{e}}$ siècle) ", LesCahiers du Centre de recherches historiques, $\mathrm{n}^{\circ} 23,1999$ [en ligne], http:// journals.openedition.org/ccrh/2162 [lien valide en novembre 2021].

11. MEYZIE Vincent, "Les édifices de la justice royale entre l'État et la Ville à la fin du $\mathrm{XVIII}^{\mathrm{e}}$ siècle : le cas des présidiaux limousins et périgourdins ", in CASSAN Michel \& HOLLANDER Paul d' (dir.), Temporalités, $\mathrm{n}^{\circ} 4$, «Espaces et pouvoirs. Édifices et cortèges de l'Antiquité à nos jours ", Limoges, Presses universitaires de Limoges, 2007 ; MEYZIE Vincent, «La matérialisation contrariée du pouvoir monarchique dans la cité : le cas des édifices de la justice royale de rang second au XVIII ${ }^{e}$ siècle ", in HOULLEMARE Marie \& ROUSSEL Diane (dir.), Les Justices locales et les justiciables. La proximité judiciaire en France, du Moyen Âge à l'époque moderne, Rennes, PUR, 2015, p. 141-155.

12. Archives départementales de la Haute Vienne (ci-après AD HV), fonds des Ponts et Chaussées, C 703 .

13. DELHOUME Didier, «Les vicomtes de Limoges et l'abbaye : difficultés et enjeux d'un pouvoir urbain ( $\mathrm{x}^{\mathrm{e}}$-XIV ${ }^{\mathrm{e}}$ siècle) », in ANDRAULT-SCHMITT Claude (dir.), Saint-Martial de Limoges. Ambition politique et production culturelle ( $\mathrm{X}^{e}$-XIII ${ }^{e}$ siècles), actes du colloque (Poitiers / Limoges, 26-28 mai 2005), Limoges, Presses universitaires de Limoges, 2006, p. 74.

14. ANDRAULT-SCHMITT Claude, "Limoges, église Saint-Michel-des-Lions ", in VERGNOLLE ELIANE, et al, Haute-Vienne romane et gothique. L'âge d'or de son architecture, Paris, Société française d'archéologie, coll. « Congrès archéologique de France », 2016, p. 158.

15. RUBEN Émile (dir.), Registres consulaires de la ville de Limoges. Premier registre, première partie: 1504-1552, Limoges, imprimerie des Chapoulaud frères, 1867-1897, p. 444, disponible en ligne https://gallica.bnf.fr/ark:/12148/bpt6k33181d.texteImage [lien valide en novembre 2021]; RUBEN Émile, Registres consulaires de la ville de Limoges. Premier registre, deuxième partie : 1552-1581, Limoges, imprimerie des Chapoulaud frères, appendice I, 1867-1897, disponible en ligne https:// gallica.bnf.fr/ark:/12148/bpt6k33182r.image [lien valide en novembre 2021].

16. Rue Haute de la Comédie, rue Gaignolle ou rue de Gorre.

17. JACOB Robert, Images de la justice : essai sur l'iconographie judiciaire du Moyen Âge à l'âge classique, Paris, Le Léopard d'or, 1994, p. 42-45.

18. JACOB Robert \& MARCHAL-JACOB Nicole, «Bâtiments judiciaires ", in ASSOCIATION FRANÇAISE POUR L'HISTOIRE DE LA JUSTICE, La Justice en ses temples: regards sur l'architecture judiciaire en France, Paris / Poitiers, Errance / Brissaud, 1992, p. 29.

19. LECLER André (abbé), Histoire de l'église et de la paroisse Saint-Michel-des-Lions à Limoges, Limoges, imprimerie Limousines Ducourtieux et Gout, 1921, p. 5-63, disponible en ligne https:// gallica.bnf.fr/ark:/12148/bpt6k145984k.texteImage [lien valide en novembre 2021].

20. «Saint Michel, Archange, défends-nous dans le péril et nous ne périrons pas dans le redoutable jugement. »

21. LECLER André (abbé), Histoire de l'église et de la paroisse Saint-Michel-des-Lions à Limoges, p. 32.

22. JACOB Robert, Images de la justice: essai sur l'iconographie judiciaire du Moyen Âge à l'âge classique, p. 42-44.

23. SOLEIL Sylvain, Le Siège royal de la sénéchaussée et du présidial d'Angers. 1551-1790, Rennes, PUR, coll. « Histoire ", 1997, p. 22.

24. MEYZIE Vincent, « La matérialisation contrariée du pouvoir monarchique dans la cité : le cas des édifices de la justice royale de rang second au XVIII ${ }^{\mathrm{e}}$ siècle ».

25. BLANQUIE Christophe, «Le palais de justice dans la France d'Ancien Régime : où siègent les présidiaux? ", in AUZÉPY Marie-France \& CORNETTE Joël (dir.), Palais et pouvoir : de Constantinople à Versailles, Saint-Denis, Presses universitaires de Vincennes, coll. «Temps et Espaces », 2003, p. 337-338. 
26. MEYZIE Vincent, «Les édifices de la justice royale entre l'État et la Ville à la fin du

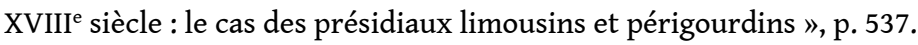

27. JACOB Robert, Images de la justice : essai sur l'iconographie judiciaire du Moyen Âge à l'âge classique, p. 196-197.

28. RUBEN Émile, Registres consulaires de la ville de Limoges. Premier registre, deuxième partie: 1552-1581, p. 301.

29. CASTAN Nicole, «La prison d'Ancien Régime", in PETIT Jacques-Guy, CASTAN Nicole \& FAUGERON Claude (dir.), Histoire des galères, bagnes et prisons. XIII ${ }^{e}-\mathrm{XX}{ }^{e}$ siècles. Introduction à l'histoire pénale de la France, Toulouse, Privat, coll. «Bibliothèque historique Privat », 1991, p. 45.

30. GUIBERT Louis, Les Confréries de pénitents en France et notamment dans le diocèse de Limoges, Limoges, imprimerie des Chapoulaud frères, 1879.

31. LECLER André (abbé), Histoire de l'église et de la paroisse Saint-Michel-des-Lions à Limoges, p. 34.

32. AD HV, fonds des Ponts et Chaussées, C 703.

33. ABDELA Sophie, La Prison parisienne au XVIII ${ }^{e}$ siècle. Formes et réformes, thèse d'histoire moderne sous la direction de Vincent Milliot (Caen, Normandie Université, 2017), Ceyzérieu, ChampVallon, coll. «Époques », 2019. En savoir plus via https://tel.archives-ouvertes.fr/tel-01699477 [lien valide en novembre 2021].

34. LEMONNIER-MERCIER Aline, Les Embellissements du Havre au XVIII siècle. Projets, réalisations, 1719-1830, Mont-Saint-Aignan, Presses universitaires de Rouen et du Havre, 2013, p. 183-208, disponible en ligne http://books.openedition.org/purh/5403 [lien valide en novembre 2021].

35. HIGELIN-FUSTÉ Audrey, «La Prison pénale en France de 1791 à 1848 : élaborer l'espace de la réclusion ", thèse d'histoire moderne sous la direction de Laurent Baridon, (Grenoble, université de Grenoble, 2011), p. 45-52, en savoir plus via https://tel.archives-ouvertes.fr/tel-01244787 [lien valide au 19 juillet 2020].

36. Transcription in LEROUX Laure, Le Présidial. Limoges (Haute-Vienne). Rapport final d'opération, vol. II, annexe 2.

37. LECLERC André (abbé), Histoire de l'église et de la paroisse Saint-Michel-des-Lions à Limoges, p. 42.

38. BADINTER Robert (préface), La Justice en ses temples: regards sur l'architecture judiciaire en France, p. 8.

39. DOUBLET François, Mémoire sur la nécessité d'établir une réforme dans les prisons et sur les moyens de l'opérer, Paris, Méquignon l'Aîné, 1791, disponible en ligne https://gallica.bnf.fr/ark:/12148/ bpt6k430355.texteImage [lien valide en novembre 2021].

40. MEYZIE Vincent, «La matérialisation contrariée du pouvoir monarchique dans la cité : le cas des édifices de la justice royale de rang second au XVIII ${ }^{\mathrm{e}}$ siècle », p. 152.

\section{RÉSUMÉS}

Dans le cadre de la transformation de l'ancien présidial de Limoges en résidence privée, le ministère de la Culture, représenté par le service régional de l'Archéologie de NouvelleAquitaine, a initié une approche archéologique de l'édifice, associant étude documentaire, suivi des travaux et analyse des élévations. Réalisée en partenariat avec une association locale, Archéa, forte d'une longue expérience concernant le bâti souterrain, cette étude a permis de confronter la matérialité des lieux aux travaux d'historiens tels que Christophe Blanquie ou Vincent Meyzie. Ces recherches révèlent un présidial exemplaire, entre héritage et innovation. La topographie 
ancienne et les sources historiques attestent de la pérennité de l'emplacement du présidial en tant que lieu de justice, contribuant à la fabrique de la ville médiévale, syncrétisme complexe de diverses entités politiques. Il participe au paysage monumental urbain ainsi qu'en témoigne la cartographie ancienne figurant l'enclos de justice. La création du présidial d'Henri II sur cette place, dans une ancienne maison presbytérale, s'inscrit donc dans une tradition civique déjà ancienne. Les transformations de l'édifice, telles que l'esquissent les sources historiques et iconographiques, font écho aux mutations de la justice d'Ancien Régime et à l'affirmation de l'État en province au cours du XVII ${ }^{\mathrm{e}}$ siècle. L'obsolescence de l'édifice, au siècle suivant, appelle sa reconstruction par un ingénieur des Ponts et Chaussées dont le projet articule le progressisme des Lumières, les fonctionnalités d'une institution polysémique et les recommandations des magistrats locaux. L'analyse archéologique éclaire l'évolution de ces ambitions en cours de réalisation, intégrant les contraintes archéologiques ou les considérations ostentatoires des occupants, pour aboutir à un archétype du palais de justice moderne.

As part of the transformation of the old présidial (judicial court of the Ancien Regime) of Limoges into a private residence, the Ministry of Culture, represented by the "service régional de l'Archéologie de Nouvelle-Aquitaine", the Regional Archaeological Service of Nouvelle-Aquitaine, initiated an archaeological approach of the building, combining documentation review, monitoring of the work and elevations analysis. Carried out in partnership with a local association, Archéa, armed with a long experience in underground building, this study enabled to compare the materiality of the sites to the works of historians such as Christophe Blanquie or Vincent Meyzie. This research reveals an exemplary présidial, between legacy and innovation. The ancient topography and the historical sources confirm the sustainability of the présidial location as a judicial place, contributing to the making of the medieval city, complex syncretism of various political entities. It took part in the urban monumental landscape as proved by the old cartography featuring the enclosure of justice. The creation of Henri II's présidial on this plaza, in a former Presbyterian house, was therefore part of a longstanding civic tradition. The transformations of the building, as outlined by the historical and iconographical sources, echoed the mutations of Ancien Regime's justice and the assertion of the State in the provinces during the $17^{\text {th }}$ century. The obsolescence of the building, during the next century, called for its reconstruction by a civil engineer whose project involved progressivism of the Enlightenment, the functionalities of a polysemous institution and the recommendations of local magistrates. The archaeological analysis sheds light on the evolution of these ambitions that were under way, taking into account the archaeological constraints or the ostentatious considerations of the occupants, leading to an archetype of the modern courthouse.

\section{INDEX}

Mots-clés : architecture judiciaire, archéologie médiévale et moderne, fabrique urbaine, monuments historiques, paysage monumental urbain

Keywords : judicial architecture, medieval and modern archaeology, making of a city, historical monuments, monumental urban landscape

\section{AUTEUR}

\section{LAURE LEROUX}

Docteur en histoire et archéologie

Responsable d'opération, bureau d'études archéologique Hadès 
laure.leroux@hades-archeologie.com 